\title{
Evaluation of changes in cervical sagittal balance and clinical parameters in patients undergoing two-level anterior cervical discectomy and fusion
}

\author{
Sebastian Podlewski ${ }^{1, A-D}$, Natalia Gołębiowska ${ }^{1, D, E}$, Maciej Radek ${ }^{2, E, F}$ \\ ${ }^{1}$ Department of Neurosurgery and Spine Surgery, Regional Hospital, Kielce, Poland \\ ${ }^{2}$ Department of Neurosurgery, Spine Surgery and Peripheral Nerves, University Clinical Hospital Military Medical Academy - Central Veterans Hospital, Łódź, Poland \\ A - research concept and design; B - collection and/or assembly of data; C - data analysis and interpretation; \\ $\mathrm{D}$ - writing the article; $\mathrm{E}$ - critical revision of the article; $\mathrm{F}$ - final approval of the article
}

Address for correspondence

Sebastian Podlewski

E-mail: sebastian.podlewski@wp.pl

Funding sources

None declared

Conflict of interest

None declared

Received on March 17, 2021

Reviewed on April 27, 2021

Accepted on May 19, 2021

Published online on September 22, 2021

\begin{abstract}
Background. Anterior cervical discectomy and fusion (ACDF) is an effective method in treating cervical sagittal imbalance and spine deformations.

Objectives. To assess whether changes of the Cobb angle, sagittal vertical axis (SVA) and T1 slope parameters affect the outcomes of a surgical treatment.

Materials and methods. A prospective study was performed in 30 patients qualified for surgical treatment for cervical degenerative disc disease. The ACDF was performed on 2 levels. Every patient underwent an X-ray examination before surgery and 3 months after the procedure. The following parameters were assessed: the $\mathrm{T1}$ slope, the angle of cervical lordosis, the SVA distance, quality of life assessed using the Neck Disability Index (NDI), and perceived pain measurement assessed using the Visual Analogue Scale (VAS).

Results. The cervical lordosis angle significantly changed $(p<0.01)$ to an average of $11.52^{\circ}$. The SVA C2-C7 distance significantly decreased $(p<0.001)$ to an average of $21.06 \mathrm{~mm}$. The value of the T1 slope angle did not change significantly before and after surgery $(p=0.706)$. After surgery, statistically significant improvement was achieved on the NDI scale for neck pain $(p<0.001)$ to an average of 9 . The NDI score significantly decreased over time $(p<0.001)$, and this change was significantly related to the increased Cobb angle $(p=0.036)$.

Conclusions. The improvement in cervical lordosis C $2-C 7$ can improve the outcomes of surgical treatment. Preoperative analysis of $X$-rays and sagittal balance parameters may be beneficial for treatment outcomes.

Key words: NDI, cervical discopathy, anterior cervical discectomy and fusion surgery, cervical sagittal balance
\end{abstract}

Cite as

Podlewski S, Gołębiowska N, Radek M. Evaluation of changes in cervical sagittal balance and clinical parameters in patients undergoing two-level anterior cervical discectomy and fusion. Adv Clin Exp Med. 2021;30(10):1007-1012. doi:10.17219/acem/137849

DOI

10.17219/acem/137849

Copyright

Copyright by Author(s)

This is an article distributed under the terms of the

Creative Commons Attribution 3.0 Unported (CC BY 3.0)

(https://creativecommons.org/licenses/by/3.0/) 


\section{Background}

Anterior cervical discectomy and fusion (ACDF), which was first described by Smith and Robinson, is considered one of the most effective surgical treatments for cervical discopathy, as it provides safe access to disc spaces from the C3 to C7 levels. ${ }^{1}$ It is a very effective method for treating spinal canal stenosis, spinal cord and nerve root compression, and when correcting cervical spine deformities with improvement of alignment of the segment in the sagittal projection. ${ }^{2}$ In Poland, the technique of the anterior approach to the cervical spine was first applied by Jan Haftek in 1967.

The ACDF is performed under general anesthesia with the patient lying in a supine position with their neck extended. The appropriate level of the spine is determined with the use of the $\mathrm{C}$-arm. A transverse incision is made on the anterolateral side of the neck and dissection of the muscles is performed. The discectomy and removal of osteophytes and ligaments is performed at the next step with the use of a microscope. To restore its height and stabilize the spine, a cage implant is placed into the intervertebral space under $\mathrm{C}$-arm guidance. ${ }^{3,4}$

The anatomical structure of the vertebrae and the shape of the disc spaces ensure the positioning of the cervical spine in the lordosis position. To assess cervical lordosis, the cervical angle is measured (Cobb angle) as follows: lines are drawn along the upper endplate of the $\mathrm{C} 2$ vertebrae and the lower endplate of the $C 7$ vertebrae and the angle between these 2 lines, where they intersect, is measured. The alternative way is to draw this line between the $\mathrm{C} 1$ and C7 vertebrae; however, the Cobb angle measured in this way is considered to be overestimated. The range of values of the Cobb angle that are considered correct has not yet been established; however, values up to $40^{\circ} \pm 9.7^{\circ}$ are accepted as proper. ${ }^{5}$ Alterations in the angle of cervical lordosis can cause neck pain or even lead to disability. ${ }^{6}$

One of the parameters used to assess cervical sagittal balance is the sagittal vertical axis (SVA) value. The SVA is a clinically significant parameter showing the correlation with quality of life assessed by the health-related quality of life (HRQOL) index. Higher SVA values are associated with greater pain and worse assessment of quality of life. ${ }^{7}$ Kato et al. reported that a SVA value greater than $35 \mathrm{~mm}$ is associated with significant intensification of neck pain after surgery. ${ }^{8}$ The SVA is the horizontal distance between the posterior superior endplate of $\mathrm{C7}$ and the vertical line from the center of the $\mathrm{C} 2$ vertebrae. The center of $\mathrm{C} 2$ is determined by the intersection of a line drawn from the base of the dens to the lower endplate of $\mathrm{C} 2$. The average SVA C2-C7 distance in healthy individuals is up to $20 \mathrm{~mm} .^{9}$ The T1 slope is the angle between the upper endplate of the T1 vertebrae and a horizontal line. This parameter is equivalent to the pelvic incidence angle in pelvic parameters. It is possible to measure $C 7$ slope as a substitute for $\mathrm{T} 1$ slope when it is impossible to visualize $\mathrm{T} 1$ vertebrae on lateral X-ray, e.g., due to a high position of the shoulders. ${ }^{10}$ The T1 vertebrae is the connection between the mobile cervical spine and the much less mobile thoracic spine. It is a segment where thoracic kyphosis turns into cervical lordosis. The $\mathrm{C} 2-\mathrm{C} 7$ lordosis angle may increase with T1 slope. ${ }^{11}$ The results of previous studies suggest that some values of T1 slope increase the risk of initiating degenerative changes. A T1 slope angle lower than $18.5^{\circ}$ may be associated with a higher risk of developing cervical myelopathy. ${ }^{12}$

Other radiological parameters that may be useful for assessing cranio-cervical balance are the chin-brow vertical axis (CBVA), cranial slope and cranial tilt. One limitation of these parameters is the necessity of radiographic examination not only of the spine but also of the skull, which increases the patient's exposure to X-rays.

\section{Objectives}

Our hypothesis is that increasing the cervical lordosis angle changes the other sagittal balance parameters (e.g., SVA, T1 slope). Changes in the aforementioned parameters may affect the outcomes of surgical treatment. The aim of this work is to assess whether changes of the Cobb angle, SVA value and T1 slope parameters affect the outcomes of surgical treatment. Our study is based on the assessment of lateral X-rays taken before surgery and 3 months post surgery in patients treated with ACDF on 2 levels.

\section{Materials and methods}

\section{Patients}

We recruited 60 patients with two- and one-level cervical discopathy. In the present study, the group of patients that underwent two-level ACDF ( $\mathrm{n}=30)$ was assessed. The inclusion criteria were as follows: age above 18 years; symptomatic two-level cervical discopathy; and the presence of at least 2 of the following symptoms of discopathy: pain in the cervical spine, radicular symptoms and neurological deficits in the upper or lower limbs. Patients who had undergone surgery of the lumbar spine were excluded from this study. Patients for whom surgery would require the use of a front plate were also excluded because the use of a plate may affect the correction of the $\mathrm{C} 2-\mathrm{C} 7$ cervical lordosis angle. Bone fusion of the operated segments takes place at the angle of local lordosis of the operated segment set by the implant. In order to avoid potential bias, this study excluded patients with previous cervical spine surgeries; implants manufactured by only 1 company were used and all patients wore the cervical collar for the same amount of time.

All patients were qualified for surgical treatment for cervical degenerative disc disease and the ACDF was 
performed on 2 levels. All patients were treated in the Department of Neurosurgery and Spine Surgery, Regional Hospital of Kielce, Poland, and were operated on by the same surgeon. Patients included in the study were operated between February 2019 and January 2020. The follow-up period was 3 months and the last follow-up examinations took place in April 2020. Three patients were excluded due to failure to attend the follow-up examination.

\section{Assessment of the sagittal balance parameters of the cervical spine}

Measurement of sagittal balance was based on assessment of lateral projection of X-rays made in a relaxed standing position. The following angles were assessed: the $\mathrm{T} 1$ slope, the angle of cervical lordosis (the curvature of the lower cervical spine C2-C7) and the SVA value (the distance between the center of the $\mathrm{C} 2$ vertebrae and the posterior superior endplate of C7). Analysis of the radiographs and measurement of the sagittal balance parameters were performed using Surgimap software (v. 2.2.15.5, OS X; www.surgimap.com). Each measurement was performed twice, and the average was taken in order to reduce measurement error. Surgimap software is characterized by a very high accuracy and low measurement error. Lafage et al. demonstrated excellent Surgimap software accuracy in their work where they assessed the parameters of lumbar sagittal balance using the mean absolute difference from validated measurements for SVA value of $2.04 \mathrm{~mm}$, and the mean difference between 2 rounds of measurement was $<0.3 \mathrm{~mm}$ for SVA. ${ }^{13}$

\section{Surgical technique and assessment of surgical outcomes}

All patients underwent surgical nucleotomy performed on 2 levels. Cervical interbody $0-4^{\circ}$ polyetheretherketone (PEEK) cages or cages with a screw locking mechanism were used during surgery. No plates were used. All patients had an X-ray taken in a lateral projection while standing in a neutral position, providing visualization of the cervical spine with the T1 vertebral body. Quality of life was assessed using the Neck Disability Index (NDI) test and perceived pain was assessed using the Visual Analogue Scale (VAS). ${ }^{14}$ All examinations were performed before surgery and after 3 months of postsurgical observation.

The following tests for significance were used for statistical analyses: Wilcoxon test (evaluation of data before and after surgery) and general estimating equations (GEE) with robust standard errors.

This study was approved by the Bioethics Committee at the Medical University of Lodz, Poland (approval No. RNN/221/19/ KE) on April 9, 2019. This research complied with the World Medical Association (WMA) Declaration of Helsinki.

\section{Results}

\section{Patient demographics}

The 30 patients included in this study (16 women and 14 men) were operated on using the two-level ACDF method. The distribution of patient age is presented in Fig. 1. Three patients ( 2 men and 1 woman) who did not report for follow-up examination were excluded from the postoperative evaluation.

The most common indication for surgical treatment was cervical discopathy with protrusion of the intervertebral disc at 2 levels, with symptoms of radiculopathy and pain and no improvement after conservative treatment (19 patients). Motor dysfunction in the form of weakness of the upper extremities was found in 11 patients. The two-level ACDF surgery was most often performed on the C5-C7 levels (21 patients). No permanent postoperative complications were found in the group of operated patients. The most common complication of treatment was dysphagia (5 patients), which resolved within 14 days after the procedure. Hoarseness occurred in 3 patients and it resolved before discharge from the Department.

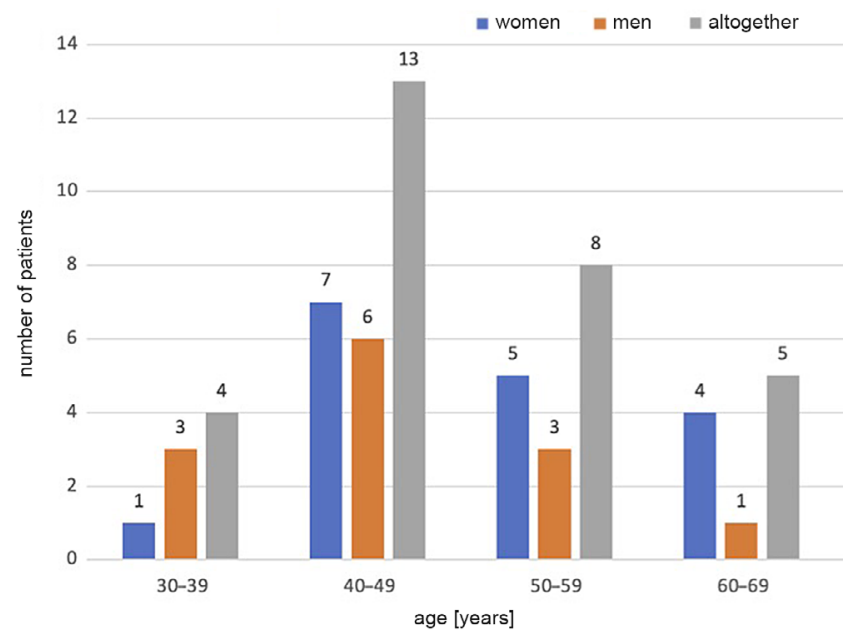

Fig. 1. Structure of the group according to age

\section{Radiography: assessment of treatment results}

Before the operation, the average cervical lordosis angle (C2-C7 Cobb angle) was $7.48^{\circ}$ (Table 1 ), the $\mathrm{T} 1$ slope was $24.43^{\circ}$ and the SVA distance was $28.36 \mathrm{~mm}$. At three-month follow-up, the cervical lordosis angle changed significantly $(\mathrm{p}<0.01)$ to an average of $11.52^{\circ}$ (Table 1). The SVA C2-C7 distance significantly decreased $(\mathrm{p}<0.001)$ to an average of $21.06 \mathrm{~mm}$ (Table 2). The value of the T1 slope angle did not change significantly before and after surgery ( $p=0.706$; however, there was an increase in the T1 slope angle with an increase in lordosis, and a decrease in its value was observed in patients whose lordosis angle decreased). 
Table 1. Summary of the sagittal balance parameters before and after surgery (for multivariate analysis)

\begin{tabular}{|l|c|c|}
\multicolumn{1}{|c|}{ Parameter } & $\begin{array}{c}\text { Before surgery } \\
(\mathbf{M})\end{array}$ & $\begin{array}{c}\text { Post surgery } \\
(\mathrm{M})\end{array}$ \\
\hline NDI score & 28.71 & 9 \\
\hline VAS score for neck pain & 7.30 & 2.59 \\
\hline Cobb angle C2-C7 & $7.48^{\circ}$ & $11.52^{\circ}$ \\
\hline SVA C2-C7 distance & $28.36 \mathrm{~mm}$ & $21.06 \mathrm{~mm}$ \\
\hline T1 slope & $24.43^{\circ}$ & $24.42^{\circ}$ \\
\hline
\end{tabular}

M - mean; NDI - Neck Disability Index; VAS - Visual Analogue Scale; SVA - sagittal vertical axis.

Before surgery, the average NDI score was 28.71 and the average VAS score for neck pain was 7.30 (VAS score for limb pain was also 7.30). After surgery, statistically significant improvement was achieved on the NDI scale $(\mathrm{p}<0.001)$ - the score increased to an average of 9 (Table 3 ). The VAS score for neck pain improved to an average of 2.59 $(\mathrm{p}<0.001)$. The VAS score for limb pain also significantly improved $(\mathrm{p}<0.001)$ to an average of 0.52 .

The multivariate model with the $\mathrm{C} 2-\mathrm{C} 7 \mathrm{Cobb}$ angle as the dependent variable and the time factor as an independent variable $(\mathrm{p}=0.002)$ showed a negative correlation with SVA value (independent variable, $\mathrm{p}<0.001$ ) and a significant correlation with the slope increase in the Th1 angle (independent variable, $\mathrm{p}=0.003$ ), in patients undergoing two-level ACDF (Fig. 2).

In the multivariate analysis with NDI as the dependent variable, and the time factor, the Cobb angle $\mathrm{C} 2-\mathrm{C} 7$ and SVA as the independent variables, the following results were obtained (Fig. 3): NDI score decreased significantly over time $(\mathrm{p}<0.001)$ and this change was significantly related to the increasing Cobb angle $(p=0.036)$, but not related to SVA changes $(\mathrm{p}=0.554)$.

Using VAS score for pain in the upper limbs as the dependent variable, and the time factor, $\mathrm{Cobb}$ angle $\mathrm{C} 2-\mathrm{C} 7$ and SVA value as the independent variables, the following results were obtained: a statistically significant reduction in the intensity of pain over the time period of the study ( $\mathrm{p}<0.001$ ), with no statistical relationship to changes in the Cobb angle $(p=0.660)$ or SVA value $(p=0.589)$.

Using VAS score for neck pain as the dependent variable, and the time factor, Cobb angle $\mathrm{C} 2-\mathrm{C} 7$ and SVA value as the independent variables, the following results were obtained: a statistically significant reduction in the intensity of neck pain $(\mathrm{p}<0.001)$, depending on the Cobb angle $(\mathrm{p}<0.001)$ and SVA value $(\mathrm{p}=0.001)$ decreasing at the same time.

Table 2. Sagittal vertical axis (SVA) values [mm] for all patients and patients separated by sex before and after surgery

\begin{tabular}{|c|c|c|c|c|c|c|c|c|}
\hline \multirow{2}{*}{ Sex } & \multirow{2}{*}{ Research phase } & \multicolumn{7}{|c|}{ Statistical parameter } \\
\hline & & M & Me & $\mathrm{Q}_{1}-\mathrm{Q}_{3}(\mathrm{IQR})$ & SD & SE & $95 \% \mathrm{Cl}$ & Min-Max \\
\hline \multirow{2}{*}{ Women } & before surgery & 25.41 & 23.50 & $17.25-30.75(13.50)$ & 10.43 & 2.61 & {$[19.86,30.97]$} & $13-50$ \\
\hline & post surgery & 18.79 & 19 & $13.50-23(9.50)$ & 6.06 & 1.51 & {$[15.56,22.02]$} & $10-28$ \\
\hline \multirow{2}{*}{ Men } & before surgery & 32.64 & 35 & $19-44(25)$ & 13.79 & 4.16 & {$[23.37,41.90]$} & $12-52$ \\
\hline & post surgery & 24.36 & 24 & $16-33(17)$ & 10.17 & 3.07 & {$[17.53,31.20]$} & $10-40$ \\
\hline \multirow{2}{*}{ Altogether } & before surgery & 28.36 & 28 & $18-39(21)$ & 12.21 & 2.35 & {$[23.53,33.18]$} & $12-52$ \\
\hline & post surgery & 21.06 & 20 & $14-28(14)$ & 8.29 & 1.60 & {$[17.78,24.34]$} & $10-40$ \\
\hline
\end{tabular}

M - mean; Me - median; IQR - interquartile range; SD - standard deviation; SE - standard error; 95\% Cl - 95\% confidence interval; Min-Max - minimummaximum.

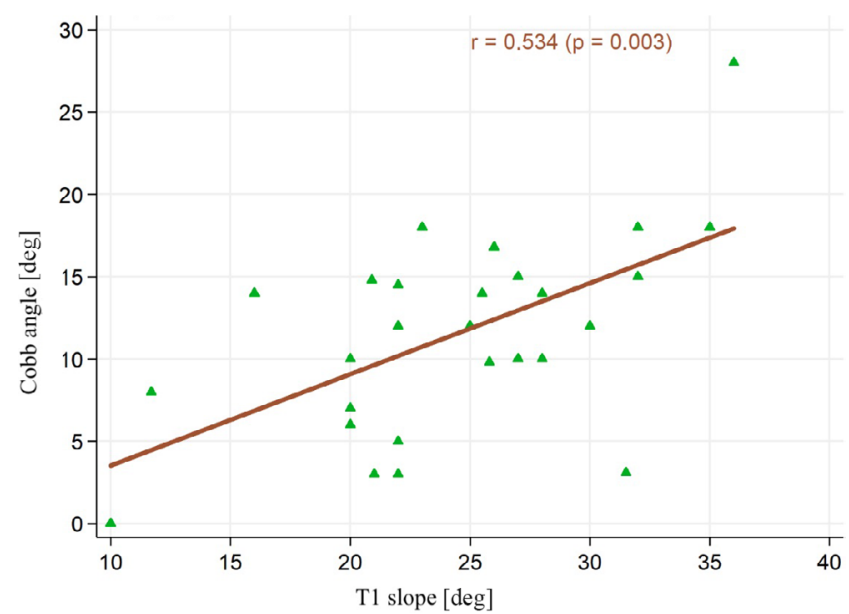

Fig. 2. Correlation of the C2-C7 cervical lordosis angle with the Th1 inclination angle in the group of respondents in the area of the neck after surgery

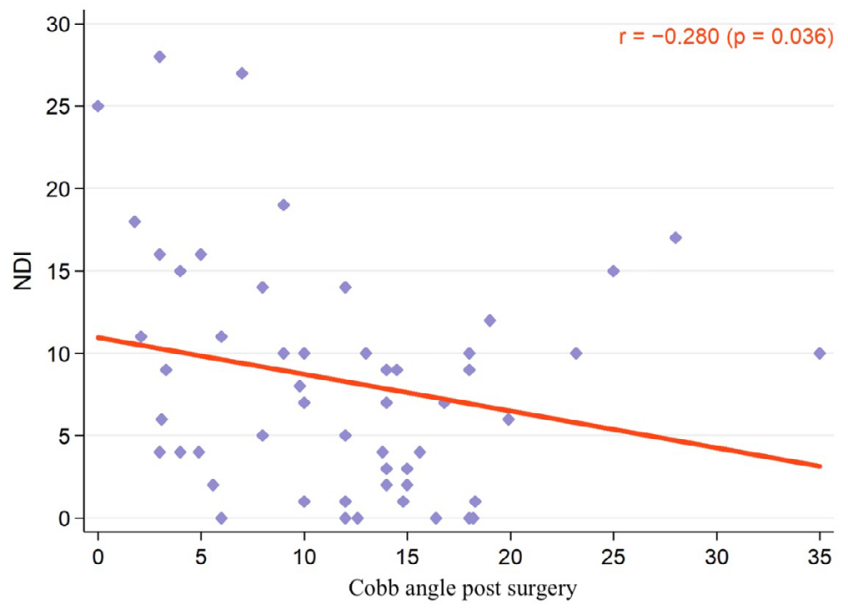

Fig. 3. Correlation of the severity of complaints according to the Neck Disability Index (NDI) with the C2-C7 lordosis angle after surgical treatment by two-level anterior cervical discectomy and fusion (ACDF) 
Table 3. The neck disability index (NDI) for all patients and patients separated by sex before surgery

\begin{tabular}{|c|c|c|c|c|c|c|c|c|}
\hline \multirow{2}{*}{ Sex } & \multirow{2}{*}{ Research phase } & \multicolumn{7}{|c|}{ Statistical parameter } \\
\hline & & M & $\mathrm{Me}$ & $\mathrm{Q}_{1}-\mathrm{Q}_{3}(\mathrm{IQR})$ & $\mathrm{SD}$ & SE & $95 \% \mathrm{Cl}$ & Min-Max \\
\hline \multirow{2}{*}{ Women } & before surgery & 32.94 & 33 & $27-39.50(22.50)$ & 8.58 & 2.15 & {$[28.36,37.51]$} & $15-46$ \\
\hline & post surgery & 9.62 & 8.50 & $4.50-12(8.50)$ & 7.57 & 1.89 & {$[5.59,13.66]$} & $1-27$ \\
\hline \multirow{2}{*}{ Men } & before surgery & 22.54 & 24 & $17-28(11)$ & 6.64 & 2.00 & {$[18.09,27.00]$} & $14-35$ \\
\hline & post surgery & 8.09 & 7 & $1-11(10)$ & 8.44 & 2.55 & {$[2.42,13.76]$} & $0-28$ \\
\hline \multirow{2}{*}{ Altogether } & before surgery & 28.71 & 28 & $20-36(16)$ & 9.30 & 1.79 & {$[25.02,32.38]$} & $14-46$ \\
\hline & post surgery & 9.00 & 7 & 3-11 (8) & 7.81 & 1.50 & {$[5.91,12.09]$} & $0-28$ \\
\hline
\end{tabular}

M - mean; Me - median; IQR - interquartile range; SD - standard deviation; SE - standard error; 95\% Cl - 95\% confidence interval; Min-Max - minimummaximum.

\section{Discussion}

The most important parameters associated with pain symptoms and the results of surgical treatment of cervical spine osteoarthritis include the T1 slope, SVA distance, and cervical lordosis angle (Cobb angle). These parameters are assessed in the lateral projection of X-ray examinations. ${ }^{15}$ It is also possible to assess sagittal balance parameters based on computed tomography (CT) or magnetic resonance imaging (MRI) examination; however, its value may be limited due to the lying position during the examination. Sagittal balance parameters are assessed in a relaxed standing position, and a change of the body position during the test may affect the obtained results. The disadvantage of the use of $\mathrm{CT}$ is the large dose of radiation that the patient is exposed to. However, CT examination can overcome some limitations of X-ray, i.e., anatomical interference of the shoulder contour. ${ }^{7}$

The analysis of changes in the values of the aforementioned parameters and the determination of the sagittal balance allows the prognosis of surgical results. Research shows that the cervical lordosis angle and SVA value (SVA C2-C7) correlate with the severity of symptoms in the treatment of cervical myelopathy. Thus, they are considered indicators of the severity of symptoms. ${ }^{16}$ Villavicencio et al. carried out work on lordotic implants and parallel interbody implants. In their research, they did not find any significant differences between the implants used in the correction of cervical lordosis. However, their results demonstrated a correlation between improvement of sagittal balance with improvement of the lordosis of the operated segment and the degree of improvement in the clinical condition. ${ }^{17}$

The parameters of the sagittal balance of the cervical spine, similarly to the lumbar-pelvic parameters, show mutual dependencies. In this study, a statistically significant correlation was demonstrated between the cervical lordosis angle and the T1 slope (C7) and a negative correlation with the SVA value (SVA C2-C7). After nucleotomy with anterior stabilization (fusion) at 2 levels and 3 months of follow-up, both an increase in the C7 cervical lordosis angle and a shortening of the SVA distance were found.
Gills et al. analyzed sagittal parameters in patients after ACDF operations were performed on 1 and 2 levels. In their study, they used measurements of the C2-C7 lordosis angle, T1 slope, disc space height, operated segment lordosis angle, and SVA C2-C7 value. The follow-up observations were made 6 weeks and 1 year after the surgical treatment. In the group of patients operated on at 2 levels, a statistically significant correlation between the lordosis angle and change in SVA C2-C7 value was observed. A similarly significant relationship was shown in the entire study group between the $\mathrm{T} 1$ slope and the SVA C2-C7. ${ }^{18}$

Changes in the sagittal balance correction value did not significantly affect perceived upper limb pain. The degree of decompression of the nerve roots is likely one of the most important factors in the reduction of nerve root symptoms. However, a significant relationship was observed between the reduction of symptoms assessed using the NDI questionnaire and the change in the angle of cervical lordosis C2-C7. A similar relationship was found for the VAS score for neck pain. A statistically significant improvement in the VAS score was demonstrated in the case of changes in the angle of cervical lordosis $(p<0.001)$ and the SVA $\mathrm{C} 2-\mathrm{C} 7$ value $(\mathrm{p}=0.001)$ after surgery.

Tang et al. evaluated 113 patients operated on using long segment posterior fixation in the course of cervical stenosis or myelopathy. In their methodology, they assessed the cervical lordosis angle $\mathrm{C} 1-\mathrm{C} 2, \mathrm{C} 2-\mathrm{C} 7, \mathrm{SVA}$ $\mathrm{C} 2-\mathrm{C} 7$, SVA $\mathrm{C} 1-\mathrm{C} 7$, and the line of the center of gravity of the head. They confirmed the positive correlation between the $\mathrm{C} 2-\mathrm{C} 7$ cervical lordosis angle and improvement in NDI values $(\mathrm{r}=0.20, \mathrm{p}=0.036)$. When analyzing the relationship between the SVA (C2-C7) distance and NDI, NDI increased significantly, with a SVA value greater than $40 \mathrm{~mm}^{\text {? }}$

Divi et al. analyzed the results of surgical procedures in patients treated using anterior stabilization of the cervical spine covering 1-3 adjacent segments. A total of 249 patients after ACDF surgery were included in their study and followed up for over 1 year. One of the important parameters used in their methodology was the difference between the T1 slope and the cervical lordosis (CL) angle (parameter T1-CL). This parameter showed a statistically significant relationship with 
the results of surgical treatment. Thus, the authors confirmed the correlation of the T1-CL value with perceived pain assessment using both, the VAS score for neck pain and the NDI score $(\mathrm{p}<0.05)$. This relationship was even stronger when there was a deformity of the cervical spine before the start of treatment. ${ }^{19}$ The work of Iyer et al. showed that the sagittal balance parameters, i.e., the CL angle, T1 slope and T1-CL difference, were related to preoperative NDI score. Higher values of the CL angle $(r=0.277, p=0.009)$ and higher values of the Th1 angle $(r=-0.273, p=0.011)$ correlated with lower patient scores on the NDI scale. ${ }^{20}$ Gum et al. assessed the angle of CL in 101 patients treated using the ACDF method over a two-year follow-up period. They also found that the parameters were correlated with clinical results. ${ }^{21}$ The analysis carried out by the authors of the present study showed that obtaining a postoperative CL angle of at least $6^{\circ}$ predicted improvement in NDI score by at least 8 points.

\section{Limitations}

There are a few limitations of this study. First, extension of the follow-up period would be beneficial for a deeper analysis of the study results. Second, including patients operated on at more levels in the study group would allow for a more complete assessment of changes in sagittal balance parameters. Additionally, including patients operated with the use of a plate would allow for comparison of the results and selection of the best method of surgical treatment.

\section{Conclusions}

Based on the results of this work, we conclude that improvement in cervical lordosis $\mathrm{C} 2-\mathrm{C} 7$ can improve surgical outcomes (in terms of NDI and VAS assessment of neck pain). However, the problem of cervical sagittal balance and its impact on treatment outcomes remains un resolved. There are only a few publications confirming the correlation of sagittal balance with the clinical status of patients after ACDF surgery. It is advisable to supplement the above conclusions with research in relation to long segment fixation (above 2 levels) and to extend the observation period.

\section{ORCID iDs}

Sebastian Podlewski (1) https://orcid.org/0000-0003-3901-1885 Natalia Gołębiowska (1) https://orcid.org/0000-0002-6723-9003 Maciej Radek (1) https://orcid.org/0000-0003-3544-1482

\section{References}

1. Smith GW, Robinson RA. The treatment of certain cervical-spine disorders by anterior removal of the intervertebral disc and interbody fusion. J Bone Joint Surg Am. 1958;40-A(3):607-624. PMID:13539086

2. Shriver MF, Lewis DJ, Kshettry VR, Rosenbaum BP, Benzel EC, MrozTE. Pseudoarthrosis rates in anterior cervical discectomy and fusion: A metaanalysis. Spine J. 2015;15(9):2016-2027. doi:10.1186/1471-2288-12-181
3. Bakhsheshian J, Mehta VA, Liu JC. Current diagnosis and management of cervical spondylotic myelopathy. Global Spine J. 2017;7(6):572-586. doi:10.1177/2192568217699208

4. Kang MS, Kim KJ, Bae JS, Jang IT. Treatment of two level artificial disc replacement for cervical spondylotic myelopathy. J Minim Invasive Spine Surg Tech. 2018;3(1):34-38. doi:10.21182/jmisst.2017.00269

5. Roussouly P, Nnadi C. Sagittal plane deformity: An overview of interpretation and management. Eur Spine J. 2010;19(11):1824-1836. doi:10. 1007/s00586-010-1476-9

6. McAviney J, Schulz D, Bock R, Harrison DE, Holland B. Determining the relationship between cervical lordosis and neck complaints. J Manipulative Physiol Ther. 2005;28(3):187-193. doi:10.1016/j.jmpt. 2005.02.015

7. Tang JA, Scheer JK, Smith JS, et al. The impact of standing regional cervical sagittal alignment on outcomes in posterior cervical fusion surgery. Neurosurgery. 2012;71(3):662-669;discussion 669. doi:10. 1227/NEU.0b013e31826100c9

8. Kato M, Namikawa T, Matsumura A, Konishi S, Nakamura H. Effect of cervical sagittal balance on laminoplasty in patients with cervical myelopathy. Global Spine J. 2017;7(2):154-161. doi:10.1177/2192 568217694011

9. Iyer S, Lenke LG, Nemani VM, et al. Variations in sagittal alignment parameters based on age: A prospective study of asymptomatic volunteers using full-body radiographs. Spine (Phila Pa 1976). 2016;41(23): 1826-1836. doi:10.1097/brs.0000000000001642

10. Tamai K, Buser Z, Paholpak P, Sessumpun K, Nakamura H, Wang JC. Can C7 slope substitute the T1 slope? An analysis using cervical radiographs and kinematic MRIs. Spine (Phila Pa 1976). 2018;43(7):520-525. doi:10.1097/BRS.0000000000002371

11. Park JH, Cho CB, Song JH, Kim SW, Ha Y, Oh JK. T1 slope and cervical sagittal alignment on cervical CT radiographs of asymptomatic persons. J Korean Neurosurg Soc. 2013;53(6):356-359. doi:10.3340/ jkns.2013.53.6.356

12. Sun J, Zhao HW, Wang J, Xun L, Fu NX, Huang H. Diagnostic value of T1 slope in degenerative cervical spondylotic myelopathy. Med SciMonit. 2018;24:791-796. doi:10.12659/msm.906417

13. Lafage R, Ferrero E, Henry JK, et al. Validation of a new computerassisted tool to measure spino-pelvic parameters. Spine J. 2015;15(12): 2493-2502. doi:10.1016/j.spinee.2015.08.067

14. Misterska E, Jankowski R, Glowacki M. Cross-cultural adaptation of the Neck Disability Index and Copenhagen Neck Functional Disability Scale for patients with neck pain due to degenerative and discopathic disorders: Psychometric properties of the Polish versions. BMCMusculoskelet Disord. 2011;12(1):84. doi:10.1186/1471-2474-12-84

15. Ling FP, Chevillotte T, Leglise A, Thompson W, Bouthors C, Le Huec JC. Which parameters are relevant in sagittal balance analysis of the cervical spine? A literature review. Eur Spine J. 2018;27(Suppl 1):8-15. doi:10.1007/s00586-018-5462-y

16. Lin T, Wang Z, Chen G, Liu W. Is cervical sagittal balance related to the progression of patients with cervical spondylotic myelopathy? World Neurosurg. 2020;137:e52-e67. doi:10.1016/j.wneu.2019.12.148

17. Villavicencio AT, Babuska JM, Ashton A, et al. Prospective, randomized, double-blind clinical study evaluating the correlation of clinical outcomes and cervical sagittal alignment. Neurosurgery. 2011;68(5):1309-1316;discussion 1316. doi:10.1227/NEU.0b013e31820 b51f3

18. Gillis CC, Kaszuba MC, Traynelis VC. Cervical radiographic parameters in 1- and 2-level anterior cervical discectomy and fusion. JNeurosurg Spine. 2016;25(4):421-429. doi:10.3171/2016.2.SPINE151056

19. Divi SN, Bronson WH, Canseco JA, et al. How do C2 tilt and C2 slope correlate with patient reported outcomes in patients after anterior cervical discectomy and fusion? Spine J. 2021;21(4):578-585. doi:10. 1016/j.spinee.2020.10.033

20. Iyer S, Nemani VM, Nguyen J, et al. Impact of cervical sagittal alignment parameters on neck disability. Spine (Phila Pa 1976). 2016;41(5): 371-377. doi:10.1097/BRS.0000000000001221

21. Gum JL, Glassman SD, Douglas LR, Carreon LY. Correlation between cervical spine sagittal alignment and clinical outcome after anterior cervical discectomy and fusion. Am J Orthop (Belle Mead NJ). 2012; 41(6):E81-E84. PMID:22837996 